\title{
Commonplace
}

\section{Clarivate, ProQuest, and our Resistance to Commercializing Knowledge}

Gabriel Stein, Travis Rich, Zach Verdin, Catherine Ahearn

Published on: May 19, 2021

DOI: $10.21428 / 6 f f d 8432 . f b 0245 f f$

License: Creative Commons Attribution 4.0 International License (CC-BY 4.0). 


\section{The Business of Knowing}

The dominant commercial model in scholarly publishing isn't serving the academy or humanity well, and instead extracts enormous profits from a mostly publicly-funded endeavor, $\underline{1}, \underline{2}$ replicating society's inherent biases in its assessments of quality. $\underline{3}$ It must be met, if not with a replacement, then with viable alternatives that center the public good over profit, diverse perspectives over ivory tower monocultures, and effective communication over monetizable assets.

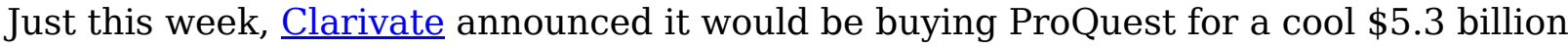
in cash and equity. $\underline{4}$ The announcement is only the latest in a series of recent acquisitions in the scholarly publishing space leaving many rightfully wondering who all of this consolidation is really benefitting. As a quick Google search will remind us, Elsevier isn't a publishing company anymore, it's "an information analytics business." They've learned from Silicon Valley that content isn't king: the data it generates is. These days, Elsevier and other major publishing companies operate more like Clarivate, an analytics company that not only mines data from their own products and services, like Web of Science, but also privatizes open data sets to their advantage. Soon enough, most research will be "open," but it won't be without cost. If the academy becomes evermore intertwined with the business of selling analytics for profit, $\underline{5}, \underline{6}$ our decisions as researchers, archivists, and publishers will become even less aligned with the needs of knowledge production and more aligned with the needs of appeasing commercial algorithms that have different definitions of "success." The impacts of the corporatization of information and the prioritization of data over people have already been felt by the news, retail, and entertainment industries. Moves driven by data analytics are good for business but potentially devastating for the health of ecosystems and the people who comprise them. And academic publishing is next (indeed, if it hasn't already been happening for years).

Among other downsides, the effect of this business model transformation will be to encode the ecosystem's existing biases into the analytics products themselves, making the biases less visible. $\underline{7}$ We can look to the behaviors of researchers, readers, and reviewers and see the disparity between what's good for business and what's actually needed. These groups want to read, find, produce, and engage with useful scholarship. Unfortunately, without a compelling alternative, the incumbent power of corporations will continue to prioritize numbers and memberships, carrying us further and further from the needs of a productive, equitable, accessible publishing ecosystem. 


\section{A Window}

We have an opportunity to avoid this fate due to a window cracked open during the coronavirus pandemic. In the face of COVID-19, the decisions driving science publishing shifted in focus away from impact for tenure and promotion packages $\underline{8}$ to impact towards a single goal: getting humanity through the pandemic. This brought about amazing changes in how we communicate knowledge and presents a rare chance to course-correct towards a system that's more open, flexible, and resistant to the corporatization of knowledge.

Preprints, once marginalized in all but a few disciplines, are now flourishing in traditionally resistant fields. $\underline{9}, \underline{10}$ Researchers across the globe and disciplines are demanding shorter and shorter review times on work that's evermore timely $\underline{11}$ and, in many cases, making do with informal and rapid evaluations of preprints conducted independently of a traditional journal submission process. At the same time, this rapid sharing of knowledge is being picked up by journalists and news outlets in their mission to inform an increasingly concerned and curious public, demonstrating the value and impact of open science like never before.

This emergent model, often described as Publish, Review, Curate (PRC), $\underline{12}$ is shifting the Overton window on what constitutes a valuable contribution to knowledge. Yes, there are dangers and downsides to this rapid communication of information especially in an age of disinformation and the mainstreaming of conspiracy - but these are challenges to solve for instead of deterrents away from the PRC model altogether. To that end, groups like PREReview, Peer Community_In... Sciety, and Rapid Reviews: COVID-19 (RR:C19) are seeing dramatic uptake of their models, and increasing interest from academics, the press, and the public as resources that can help make sense of the COVID-driven glut of preprints and, potentially, much else.

In a future where review happens in the open, and where editorial data is accessible and researchers and institutions shape it to fit their needs rather than the needs of algorithms, commercial publishers will still exist. But they'll be incentivized to innovate and serve researchers and institutions to earn their keep, rather than 
extracting 35\% margins $\underline{13}$ through monopolistic rent-seeking. In this possible future, we would have tipped the balance from an extractive knowledge-creation ecosystem designed to serve the profit margins of conglomerates to a healthy one led by researchers and institutions in service of the public good.

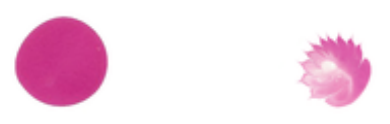

\section{The Flood}

Little will change unless researchers believe that they can secure a future for themselves by participating in PRC publishing models. For that change to happen, tenure and promotion committees must be willing to value PRC-produced research as highly as papers published in traditionally elite journals. But few people submit PRCproduced research to those committees, so why would they consider valuing it? Simply put, the dam won't break until researchers demand that their institutions value PRCproduced research.

How do we break the dam? Turn a trickle into a flood. A whole generation of researchers are going to build their careers on work done in the urgency of the pandemic and within the PRC model. Tenure committees are already needing to adapt their practices to accommodate research preprinted and evaluated on accelerated timelines in alternative models - especially research that so clearly contributes to the public good. $\frac{14}{1}$ In addition to offering more opportunities for a more diverse group of researchers to participate and have their contributions valued and recognized, it is associated with more attention than traditional models. $\underline{15}$ It's no less effective at producing quality contributions to scientific literature, $\underline{\underline{16}}$ and potentially much more so. $\underline{17}$ It can be a much faster process than traditional publishing $\underline{18}$ with more satisfying feedback loops. $\underline{19}$ Additionally, it has the potential to offer a broader range of higherquality assessment metrics, and to be far cheaper for institutions than traditional publishing processes.

Deals like the one between Clarivate and ProQuest likely won't stop happening any time soon. But, what the scholarly publishing ecosystem needs is hundreds more groups turning to community-driven models like PRC built on top of open 
infrastructure. As examples like RR:C19 and PREreview demonstrate, the PRC model has a lot going for it that can be catalytic and compounding, continuing the perception shift sparked by the pandemic and offering a real alternative to the profit-centric system currently in place.

\section{We Each Have a Role}

No matter our position within the academic publishing ecosystem, we can each play an important role in bringing about and supporting this alternative path.

Academics and Researchers can engage in a PRC process and offer feedback to organizations like the Knowledge Futures Group,$\underline{20} \underline{\text { eLife, }}$, and Invest in Open

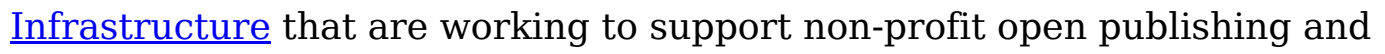
infrastructure alternatives.

Tenure and promotion committee members as well as university administrators can move to update guidelines (and redirect budgets) so they better align with University missions, prize open access, and create value systems that reward all contributions rather than just elite publications.

Professors can more frequently incorporate lessons and advice on publishing and reviewing to graduate students (and even undergraduates) so that learning about the healthy communication of their work is experienced in tandem to conducting the work itself.

Foundations and other funding bodies can update their policies to require not just openness of the research they fund, but also a contribution to the health of knowledge exchange. And, they can work to fund PRC and other alternative models as a programmatic priority.

And finally developers of open infrastructure can help make it less costly to experiment with new models by providing shared tools, as well as developing ways to more effectively measure the impact of research published outside of for-profit (but "high-impact") publications. If we move right now to develop ways to measure impact within the PRC model and rapidly accelerate its adoption with validation from the 
kinds of senior researchers who sit on tenure committees, we can turn this brief, forced opening into lasting change.

In Clarivate's issued press release, its Executive Chairman and CEO, Jerre Stead, states, "we will enable our customers to solve the world's most complex challenges." The validity of this sentiment is surely dependent on your view of what these challenges are, who should be solving them, and what form(s) such solutions should take. In any case, let's work together to ensure Clarivate will, at least, inspire us to define these solutions and paths forward for ourselves, if not enabled by them, then motivated by what this most recent acquisition - and those that came before it portends.

\section{Footnotes}

1. Monbiot, G. (2018, September 13). Scientific publishing is a Rip-off. we fund the research - it should be Free. The Guardian, link.

2. Buranyi, S., 2021. Is the staggeringly profitable business of scientific publishing bad for science? The Guardian, link.

3. Lee, C.J., Sugimoto, C.R., Zhang, G. and Cronin, B. (2013), Bias in peer review. J Am Soc Inf Sci Tec, 64: 2-17. https://doi.org/10.1002/asi.22784

4. Read Clarivate's press release here: https://clarivate.com/news/clarivate-toacquire-proquest/ $\triangleq$

5. Basken, Paul. "Elsevier Is Becoming a Data Company. Should Universities Be Wary?" Chronicle of Higher Education, 22 July 2020, link..

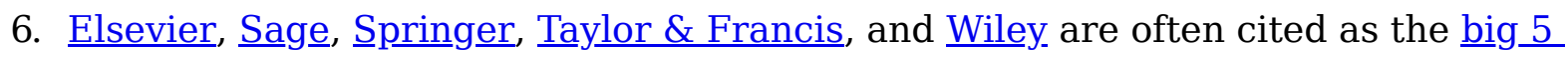
for-profit academic publishers. Their outsized profit margins; acquisitions of smaller, often community-built and/or open source products; and evolution into analytics

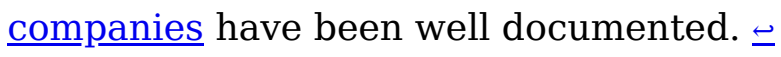


7. Lee and Low Books, "Where is the Diversity in Publishing? The 2019 Diversity Baseline Survey Results.” The Open Book Blog. January 28, 2020. https://blog.leeandlow.com/2020/01/28/2019diversitybaselinesurvey $1 \subseteq$ 8. Which is to say, impact based on pre-determined and detached definitions of "impact" and success that further perpetuate this profit-driven system. $\bullet$ 9. Fraser, N., Brierley, L., Dey, G., Polka, J. K., Pálfy, M., Nanni, F., \& Coates, J. A. (2020, May 23). Preprinting the COVID-19 pandemic. bioRxiv. https://doi.org/10.1101/2020.05.22.111294

10. Belli, B., 2021. Preprint server founded by Yale now leading source for COVID19 discoveries. YaleNews, link.

11. Horbach, Serge P. J. M. (2020). Pandemic publishing: Medical journals strongly speed up their publication process for COVID-19. Quantitative Science Studies 2020 1:3, 1056-1067. https://doi.org/10.1162/qss_a $00076 \leftrightharpoons$

12. Stern BM, O'Shea EK (2019) A proposal for the future of scientific publishing in the life sciences. PLoS Biol 17(2): e3000116.

https://doi.org/10.1371/journal.pbio.3000116

13. Buranyi, S., 2021. Is the staggeringly profitable business of scientific publishing bad for science? The Guardian, link. $\triangleq$

14. Callaway, E. (2020). Will the pandemic permanently alter scientific publishing? Nature, 582(7811), 167-168. https://doi.org/10.1038/d41586-020-01520-4 15. Fu, D. Y., \& Hughey, J. J. (2019). Releasing a preprint is associated with more attention and citations for the peer-reviewed article. ELife, 8. https://doi.org/10.7554/elife.52646 $ヒ$

16. Carneiro CFD, Queiroz VGS, Moulin TC, Carvalho CAM, Haas CB, Rayêe D, et al. (2020). Comparing quality of reporting between preprints and peer-reviewed articles in the biomedical literature. bioRxiv. https://doi.org/10.1101/581892

17. Oransky, Ivan and Marcus, Adam., 2020. Quick retraction of a faulty coronavirus paper was a good moment for science. Stat News, link.

18. Fraser, Nicholas, Brierley, Liam, Gautam, Dey, Polka, Jessica K, Pálfy, Máté and Coates, Jonathon Alexis (2020). Preprinting a pandemic: the role of preprints in the 
COVID-19 pandemic. bioRxiv. https://doi.org/10.1101/2020.05.22.111294

19. Marcus, Adam, Oransky, Ivan, and Retraction Watch, 2019. Eye for Manipulation: A Profile of Elisabeth Bik. The Scientist, link. $\_$

20. The authors of this article are all employees of the Knowledge Futures Group. $\_$ 